\title{
A CRIMINALIZAÇÃO DOS MOVIMENTOS SOCIAIS ANTE A INSTALAÇÃO DE UMA HIDRELÉTRICA NO RIO URUGUAI (BRASIL): UMA DISCUSSÃO ENTRE O LEGAL E O LEGÍTIMO
}

\author{
Humberto José da Rocha*
}

Resumo: As obras de grande escala são propostas por empresas públicas e privadas através do argumento da utilidade pública e de premissas legais. As populações dos locais onde essas são instaladas se organizam em movimentos sociais que reivindicam a legitimidade de seus direitos. Nessa relação conflitiva, analisamos como a criminalização dos movimentos sociais tende a suplantar o binômio legal/legítimo estabelecendo uma assimetria nas relações de poder em favor dos proponentes dessas obras. A fundamentação teórica dialoga com a pesquisa empírica sobre o caso da instalação de uma hidrelétrica na bacia do Uruguai, no Sul do Brasil.

Palavras-chave: Criminalização; Legalidade; Legitimidade; Obras de Grande Escala.

Abstract: The large scale works are proposed for public and private companies through the public utility argument and legal premises. The populations of the places where these are installed are organized in social movements claiming the legitimacy of their rights. In this conflictive relationship, we analyze how the criminalization of social movements tends to supplant the legal/legitimate binomial establishing an asymmetry in power relations in favor of the proponents of these works. The theoretical foundation dialogues with the empirical research about the case of a hydroelectric installation in the Uruguay basin, in the south of Brazil.

Keywords: Criminalization; Legality; Legitimacy; Large Scale Works.

* Doutor em Ciências Sociais pela Universidade Estadual de Campinas (UNICAMP). Professor da Universidade Federal da Fronteira Sul (UFFS) - Chapecó, Santa Catarina, Brasil. Email: <humbertojosedarocha@yahoo. com.br>. 


\section{As obras de grande escala e os protestos no Brasil}

As intensas manifestações populares ocorridas em 2013 em diferentes partes do país já fazem parte de qualquer cronologia sociopolítica que se tente para o Brasil. Uma das marcas principais desses protestos é a pluralidade na qualidade das demandas e no perfil dos manifestantes.

Analisando o quadro de demandas que animaram esses protestos, verificamos que as obras de grande escala estão entre os principais motivos, juntamente com as questões do transporte público e da corrupção, carros-chefes das mobilizações. No tocante às obras de grande escala, este quadro foi intensificado em 2007 através de iniciativas governamentais como o Plano de Aceleração do Crescimento (PAC) prevendo obras de infraestrutura (transporte, energia, abastecimento). A decisão de que o Brasil sediaria a Copa do Mundo de Futebol (2014), anunciada no mesmo ano e a escolha do Rio de Janeiro como sede dos Jogos Olímpicos (2016), ocorrida em 2009, deram novo impulso às obras de grande escala no Brasil.

Os projetos que compõem esses três blocos de obras assumem a distinção de "obras de grande escala" em virtude de características específicas de tamanho e temporariedade implicadas nas suas construções. Em virtude da sua envergadura, reconfiguram os locais não só geográfica, mas socialmente, devido ao intenso movimento de pessoal e equipamentos presentes temporariamente nesses lugares. Outro aspecto importante neste tipo de obra é que pela sua envergadura, "articulam interesses locais, regionais, nacionais, internacionais e transnacionais" (RIBEIRO, 1987), sendo que no Brasil, essas alianças se materializam por meio das Parcerias Público-Privadas (PPP) que originam Sociedades de Propósitos Específicos (SPE), que têm sua criação em virtude da obra que pretendam instalar e operar ${ }^{1}$.

\footnotetext{
${ }^{1}$ Nos termos da Lei $n^{\circ} 11.079$, de 30 de dezembro de 2004, a qual estabelece as normas gerais para as Parcerias Público-Privadas (PPP) no Brasil.
} 
Embora essas obras de grande escala constem de projetos carregados de justificativas para sua concretização - especialmente a da utilidade pública -, é recorrente a natureza conflituosa que tem marcado os projetos recentes, o que pode ser verificado em obras dos três blocos mencionados, PAC, Copa e Olimpíadas. As obras do PAC, em maior número e de natureza diversa, têm no caso da usina hidrelétrica de energia (UHE) Belo Monte, em instalação no rio Xingu, no estado do Pará (Amazônia brasileira), a expressão mais notória do conflito entre os seus propositores e as populações locais, especialmente os indígenas. Todavia, é digno de registro que a mobilização social decorrente dessas obras é anterior às iniciativas recentes do PAC e dos megaeventos esportivos. Movimentos sociais como o MAB (Movimento dos Atingidos por Barragens), promovem mobilizações ante as obras de grande escala, especialmente as hidrelétricas, atuando em todo o país desde a década de 1970, embora recentemente, tenham adquirido maior visibilidade em decorrência das mencionadas iniciativas empresarias, especialmente o mencionado caso de Belo Monte.

Maria da Glória Gohn (2012) apresenta um resgate da história dos movimentos sociais no Brasil que remonta ao século XVIII quando das lutas pela independência. No caso das obras de grande escala, assinalamos a criação da Comissão Regional dos Atingidos por Barragens (CRAB) em 1979, decorrente da instalação da UHE Itá, em Santa Catarina, como marco para a nossa análise (GOHN, 2012: 121). Embora sejam conhecidas as mobilizações decorrentes de hidrelétricas como Sobradinho e Itaparica (rio São Francisco, no estado de Pernambuco), na década de 1970, Tucuruí (rio Tocantins, no estado do Pará) e Itaipu (rio Paraná, no estado do Paraná), na década de 1980, foi a partir da UHE Itá que o movimento social se articulou de forma sistemática.

A região da bacia do rio Uruguai apresenta uma geografia que enfatiza o argumento da vocação brasileira para a exploração da hidreletricidade, tendo em vista a abundância fluvial e o relevo de predomínio planáltico que confere aos rios a declividade que facilita os projetos hidrelétricos. Além da exploração hidrelétrica 
empreendida inicialmente pela ELETROSUL, a região também é marcada pela atividade agroindustrial a partir de grandes empresas do ramo, como a Sadia e a Perdigão, por exemplo. Este fator, ao passo que alavancou o desenvolvimento econômico da região, trouxe problemas sociais na mesma proporção, sendo que no final da década de 1970 a "crise da peste suína", aliada ao anúncio de dezenas de hidrelétricas a serem instaladas na região promoveram uma histórica mobilização social a partir de segmentos de igrejas, universidades e sindicatos rurais, refletindo na formação da CRAB, que mais tarde tomaria proporções internacionais tornando-se o Movimento dos Atingidos por Barragens (MAB) (ROCHA, 2013: 111).

Ante esse quadro, este artigo se propõe a discutir a relação conflituosa entre os propositores das obras de grande escala e os movimentos sociais contrários a essas mesmas obras, especialmente no que diz respeito à criminalização das ações de protesto. Além da revisão bibliográfica acerca do tema, nossa discussão fundamenta-se, sobretudo em pesquisa de campo que realizamos quando do doutoramento em ciências sociais, sendo que o resultado foi publicado recentemente (ROCHA, 2013). Nossas pesquisas tiveram sequência por ocasião de um projeto de pesquisa que realizamos no âmbito do P\&D 3936-003/2007 da ANEEL, intitulado "Avaliação dos resultados e proposição de modelo de elaboração de programas de remanejamento da população atingida por empreendimentos hidrelétricos". Em julho de 2011, realizamos uma pesquisa de campo para a realização de entrevistas semiestruturadas bem como testar a viabilidade de um survey específico para o desenvolvimento do referido projeto. Os entrevistados foram selecionados a partir do conhecimento empírico acumulado por ocasião da pesquisa de doutorado, desenvolvida desde 2007 sobre o tema na bacia do Uruguai.

Dos resultados qualitativos e com o aprimoramento do survey, retornamos para outra pesquisa de campo durante o mês de janeiro de 2012. Nessa ocasião, contamos com a participação de mais dezessete alunos de graduação e pós-graduação das Universidades Federal de Pelotas (UFPEL) e da Fronteira Sul (UFFS) 
que realizaram entrevistas quantitativas (survey) com 632 famílias remanejadas pelas hidrelétricas de Itá, Machadinho, Barra Grande, Campos Novos e Foz do Chapecó, sendo que os dados foram trabalhados quantitativamente através do programa SPSS. Na mesma oportunidade, podemos aprofundar a pesquisa qualitativa repetindo algumas realizadas anteriormente e entrevistando outros militantes, sendo esta a modalidade da pesquisa que fundamenta a análise deste artigo.

Este trabalho está estruturado de forma a apresentar, primeiramente, numa perspectiva teórica fundamental, a criminalização sob a luz do binômio legal/legítimo. Disto, seguiremos apoiados em pesquisa empírica que realizamos em uma dessas obras de grande escala ${ }^{2}$, através do que buscaremos apresentarosargumentosdospropositoresdessaobra, evidenciando a sua legalidade. Em seguida, apresentamos os argumentos dos movimentos sociais, em que prepondera a legitimidade, de forma a contrapor com o que foi apresentado na seção anterior. Disto, encaminhamos as nossas considerações finais. De maneira geral, procuramos demonstrar como a criminalização representa um ponto de desequilíbrio nas relações de poder na instalação dessas obras de grande escala, de forma que a reciprocidade entre legalidade e legitimidade tende a ser suplantada em favor de um dos grupos, o que pode representar, no limite, a concretização desses projetos alheiamente aos argumentos contrários.

\section{A criminalização sob a luz do binômio legal/legítimo}

As referências às obras de grande escala neste trabalho correspondem a um projeto de Estado $^{3}$ fundamentado legal

\footnotetext{
${ }^{2}$ A UHE Foz do Chapecó (855 MW) é uma hidrelétrica que integra o Programa de Aceleração do Crescimento (PAC), instalada no rio Uruguai, entre os municípios de Alpestre (RS) e Águas de Chapecó (SC).

${ }^{3}$ Neste caso seguimos a perspectiva de Poulantzas (1981), em que o autor enfatiza a "seletividade" do Estado.
} 
e economicamente através das parcerias público-privadas. Sagrando-se vitoriosa no leilão para a concessão de uso de bem público, a respectiva Sociedade de Propósito Específico (SPE) busca inserir o projeto na região determinada, num movimento apoiado na legalidade, mas que precisa obter também a legitimidade para seguir adiante. Dito de outra forma, a legalidade sobre a qual o projeto se baseia paralelo à legitimidade em relação às populações locais que podem estar sendo atingidas pelo referido projeto (SCHERER-WARREN, 2005: 84).

O binômio legalidade/legitimidade envolve aspectos políticos, jurídicos e morais, e, fundamentalmente, envolve relações de poder. Paulo Bonavides defende que "o poder legal representa por consequência o poder em harmonia com os princípios jurídicos, que servem de esteio à ordem estatal". Logo, segundo o autor, “o conceito de legalidade se situa assim num domínio exclusivamente formal, técnico e jurídico". Complementarmente, o mesmo explica que "a legitimidade é a legalidade acrescida de sua valoração", sendo que, neste conceito, "entram as crenças de determinada época, que presidem à manifestação do consentimento e da obediência" (BONAVIDES, 2011: 120-121).

Com base nisso, o binômio legal/legítimo se mostra crucial à nossa análise tendo em vista a relação entre esses aspectos. O projeto de uma obra de grande escala, legalmente constituído, precisa de legitimidade perante a sociedade para ser executado, ao passo que as demandas entendidas como legítimas por determinados grupos locais (indenizações, por exemplo), precisam encontrar amparo legal para serem atendidas.

A relação recíproca entre a legalidade (direito) e legitimidade (moral) no Estado Democrático de Direito acontece pelo uso do direito para "distribuir os pesos da argumentação e institucionalizar caminhos de fundamentação abertos a argumentações morais". Isto permite que o direito e a moral "procedimentalizada" acabem por controlar-se mutuamente (HABERMAS, 2003: 218). Todavia, ao transportar as considerações deste binômio para o caso em análise, onde a legalidade é o referencial dos propositores enquanto 
a legitimidade fundamenta o argumento primeiro dos atingidos, percebemos uma assimetria importante.

Ao adentrar no campo legal para se fazer valer, os argumentos tidos como legítimos são enquadrados institucionalmente de forma "metódica" (em correspondência com a lei em vigor), "objetiva" (mediante prova concreta), "social" (no sentido da distribuição dos papéis) e "temporal" (em relação aos prazos) (HABERMAS, 2003: 219). Logo - mesmo que Habermas não apresente suas considerações sob esta perspectiva -, no que diz respeito à nossa análise, é possível evidenciarmos a assimetria desta relação tendo em vista que enquanto os argumentos morais conferem legitimidade aos processos judiciais, na contramão, esses procedimentos legais, podem acabar por desvirtuar o essencial da argumentação moral.

Por ocasião de uma obra de grande escala, os dois agentes sociais apresentam, em certa medida, argumentações legais e legítimas. Os propositores buscam legitimar sua posição com base na suposta "necessidade"4 da obra, buscando apoio da opinião pública. Os movimentos sociais, sem serem definitivamente contrários à suposta "necessidade" da obra em questão, enfatizam a legitimidade de suas demandas através dos direitos das minorias tendo em vista a sua "condição de atingido" 5 . Nesse sentido, é pertinente outra consideração em referência ao entrelaçamento de direitos individuais e bens coletivos tendo em vista que, nesses casos, tende a aumentar "a suspeita de que o choque entre essas preferências valorativas, não racionalizáveis, privilegie os interesses mais fortes" (HABERMAS, 2003: 213).

Mesmo que essa assimetria seja explícita, vale à pena trazermos para a discussão as colocações de Boaventura de

\footnotetext{
${ }^{4}$ No caso das obras do PAC, especialmente as hidrelétricas, a necessidade de energia.

${ }^{5}$ Em outra oportunidade (ROCHA, 2010) explicamos que a "condição de atingido" por uma obra de grande escala corresponde a uma construção social que se dá segundo variáveis (política, economia e cultura) a serem observadas em cada caso específico.
} 
Sousa Santos no que se refere às possibilidades de enfrentamento de grupos desfavorecidos em busca de uma emancipação. Mesmo diante da ilegalidade que possa limitar a expressão da legitimidade das demandas expressas através das manifestações públicas, com base no que chama de "sociologia das emergências", ele aponta para a possibilidade de substituição de um vazio do futuro por um futuro de possibilidades. Essa substituição vai da utopia à concretude através do que o autor chama de "atividades de cuidado", sendo que a emancipação pode passar por essas mobilizações sociais (SANTOS, 2002).

Essa emancipação que tem sua trajetória da utopia para a realidade passa em algum momento pela legalidade, porém, não tem necessariamente todo o seu caminho trilhado sobre ela. Sobre a possibilidade de emancipação pelo viés judicial, Boaventura de Sousa Santos (2003) explica que a recorrência ao direito formal implica na compreensão de que este, além das prerrogativas técnicas como as apresentadas acima, pertence a um horizonte político mais vasto. Disto, considerando que o legal e o ilegal são condicionados pelo direito, podemos considerar algumas práticas de manifestação tidas como ilegais - ocupação de canteiros de obras ou interdição de vias públicas - como "um meio de lutar por uma legalidade alternativa", que, embora não esteja em plena concordância com a legislação vigente, pode significar um caminho para uma emancipação - via direito - para aqueles grupos que estão à margem no que tange à "legalidade" das suas demandas (SANTOS, 2003).

Então, sob a luz dessa reciprocidade legal/legítimo, no momento em que o legítimo defendido pelos movimentos sociais e expresso nas manifestações públicas choca-se com o legal que ampara os propositores dessas obras de grande escala, a criminalização tem constantemente ocupado lugar de destaque na discussão. Do ponto de vista jurídico, o "crime" se configura através de um "fato típico" que precisa ser composto por uma "conduta" de ação ou omissão humana, em que seu "resultado" modifique o mundo exterior. Se a relação de "causalidade" entre 
a conduta e o resultado encontrar correspondência exata na lei, então esta será "tipificada" como "criminosa" (MIRABETE, 2003).

Não obstante a prerrogativa técnica do Direito mereça lugar de destaque na nossa análise, tendo em vista que pretendemos uma discussão sociológica envolvendo o Direito - e não uma discussão essencialmente jurídica -, se nos restringirmos apenas à perspectiva de que o "crime é a concreção de uma conduta legalmente definida como tal, já não poderemos investigar a criminalidade como um fenômeno social, mas apenas enquanto definida normativamente" (ANDRADE, 1997: 219-220). Portanto, nos parece mais proveitoso analisarmos o aspecto criminal da nossa discussão seguindo a linha da "criminologia crítica", segundo a qual, o termo "criminalização" encontra fundamento nas teorias do labelling approach (que numa tradução aproximada podemos chamar de "abordagem rotulante") e do "conflito", a partir do que a criminalização envolve uma construção que não pode ser entendida apenas do ponto de vista dos criminosos, mas de uma etiquetagem ou rotulagem desses, o que tende a corresponder aos interesses dos grupos mais poderosos (BARATTA, 2002).

Então, utilizando um caso concreto para operacionalizar as ideias expostas até aqui, temos um quadro onde os movimentos sociais, apoiados na legitimidade de suas demandas, "lutam por uma legalidade alternativa", como referencia Santos (2003). Nesse sentido, a principal forma de luta continua sendo a pressão popular, tanto que ações de mobilização social, como passeatas, acampamentos nas vias de acesso e ocupação de canteiros de obras, por exemplo, têm sido percebidas nos diferentes locais de conflito.

Em resposta a esses movimentos de pressão popular, os propositores buscam o embasamento legal procurando tipificar as ações desses movimentos sociais nos diferentes locais de conflito como "crimes". Dentre as tipificações mais recorrentes verificamos: "Dano", "Esbulho possessório", "Furto simples e qualificado", "Sequestro e Cárcere Privado", "Formação de Quadrilha", "Incitação ao crime" e "Apologia ao crime", tudo previsto no Código Penal Brasileiro (MNDH, 2006: 14-15). 
É neste momento em que a criminalização representa o choque - e o desequilíbrio - entre o legal e o legítimo. Então, é importante que compreendamos a criminalização segundo as duas perspectivas distintas, o que buscaremos apresentando a visão dos propositores e em seguida os argumentos dos movimentos sociais acerca de uma mesma obra de grande escala.

\section{A legalidade evocada pelos propositores}

As obras de grande escala envolvem seus propositores e os movimentos sociais sob uma perspectiva conflitiva onde o choque entre o legal e o legítimo reflete na criminalização das ações de manifestação pública. Disto, partimos para a análise de um caso concreto de forma a dar voz às duas partes - seguindo os parâmetros jurídicos - sendo que nesta seção apresentaremos a posição dos propositores de uma dessas obras, a dizer, uma usina hidrelétrica que compõe o Plano de Aceleração do Crescimento (PAC).

A UHE Foz do Chapecó é uma usina hidrelétrica com potência de $855 \mathrm{MW}$ que foi instalada no rio Uruguai na altura dos municípios de Águas de Chapecó (SC) e Alpestre (RS). A referida obra de grande escala teve seu projeto executado entre os anos de 2001 e 2010 e provocou o remanejamento de aproximadamente três mil famílias em decorrência do alagamento para a formação do reservatório (ROCHA, 2013). A obra foi executada por uma Sociedade de Propósito Específico (SPE) que reuniu o governo federal (Furnas), uma holding brasileira (Companhia Paulista de Força e Luz - CPFL) e o governo do Rio Grande do Sul (Companhia Estadual de Energia Elétrica - CEEE-RS).

Dentre as falas que colhemos quando da pesquisa de campo, mostrou-se contundente a manifestação de um diretor adjunto da Sociedade de Propósito Específico (SPE) responsável pela obra. Perguntado sobre eventuais medidas de "criminalização" dos movimentos sociais no caso da obra em questão, o diretor nos explicou em entrevista que 
esse termo [criminalização] foi criado [pelo movimento social] para agir junto aos direitos humanos no sentido de que nós estaríamos perseguindo-os de alguma forma. Na realidade não é isso. Me diga uma coisa: se você vai lá e implanta um marco [topográfico], protegido por lei, e daí os caras vão lá e derrubam. Daí se faz um Boletim de Ocorrência (BO) e se volta lá pra plantar o marco, daí, vão lá algumas pessoas e ameaçam o pessoal da empresa que está fazendo o seu trabalho. Isso está correto?

As palavras do entrevistado além de corroborarem a natureza conflitiva da questão, ratificam a dicotomia legal/ legítimo, tornando nítido que os propositores buscam encampar a legalidade para "tipificar" as ações dos manifestantes. Nessa perspectiva, questionamos o diretor da empresa a respeito do significado que a criminalização - ou, medidas para garantir o trabalho da empresa, conforme defendeu o entrevistado - pode representar enquanto inibidora da resistência organizada mediante o acionamento judicial dos movimentos sociais contrários às obras de grande escala. Sobre este aspecto o entrevistado procurou apresentar sua posição ilustrando:

Então, está lá a pessoa, no ato, vai lá, arranca um marco [topográfico], ameaça os trabalhadores, em alguns casos até botam fogo em máquinas. [...] São fatos que ocorreram e o Boletim de Ocorrência (BO) aponta o nome do sujeito, pois o Movimento [Social] não tem CNPJ para ser acionado. Não se trata de criminalizar um Movimento. Todas as ações contra essas pessoas é por algum fato ocorrido, testemunhado, daí se cita nominalmente. Nunca é contra o $\mathrm{MAB}$, até porque, juridicamente ele não existe, mas os fatos apontados em BO são verídicos, testemunhados, e daí, contra aqueles que cometeram.

A explicação do diretor, que conta com mais de três décadas de experiência no campo das obras de grande escala, segue na linha da legalidade para assinalar a dificuldade de acionamento 
judicial do movimento social devido à sua forma de organização desinstitucionalizada, atuando como movimento de massa e sem registro cartorial. Legalmente, o argumento é preciso, todavia, precisa ser contraposto com a possibilidade de que, nesses casos, “a criminalização não é individual, é sempre coletiva. O castigo de um militante não é pessoal e individual, mas é parte de uma criminalização geral dos movimentos que lutam pela emancipação social" (BUHL; KOROL, 2008: 12).

$\mathrm{Na}$ mesma linha, mas retomando a ideia da análise conjuntural, é importante levar em conta que, nesses casos, a "violência de grupo e a institucional são consideradas apenas em relação a ações de pessoas individuais, e não no contexto do conflito social que elas expressam". Dessa forma, as atenções seja da polícia, da mídia, da comunidade - recaem não só sobre os militantes processados, mas sobre esses em relação ao movimento social, que acaba sendo o "criminoso em evidência". Então, se não for considerado o contexto do suposto crime, mas apenas o crime e o criminoso em si, corre-se o risco de se cair na armadilha simplificante da "descontextualização e despolitização sociais", em favor de quem acusa (ANDRADE, 2003).

Para além do alvo do processo de criminalização, que seja individual, sobre o militante, ou institucional, sobre o movimento social - embora este não constitua pessoa jurídica -, no que diz respeito à parte que acusa, baseado na legalidade, outro ponto se mostra importante na discussão. Sendo que as Parcerias PúblicoPrivadas (PPP) originam Sociedades de Propósitos Específicos (SPE) reunindo sobre a mesma pessoa jurídica instituições privadas e estatais, em que medida esta aproximação entre a empresa que propõe e o Estado que julga, pode influenciar no aspecto judicial, sobretudo, no tocante à criminalização?

Com base no caso concreto, além da ocupação do canteiro e o arrancamento de marcos topográficos, enquanto estratégias de pressão popular, o movimento social promoveu outras manifestações no local da obra. Um episódio digno de nota se deu quando os manifestantes obstruíram vias de acesso ao canteiro de 
obras em julho de 2008. Segundo informações da Polícia Militar6, “assim que o MAB bloqueou o acesso, o Comando do $2^{\circ}$ Batalhão de Polícia Militar deslocou cerca de 40 policiais militares para o local". Dentre os policiais deslocados, estavam o "Pelotão de Patrulhamento Tático, Canil e Cavalaria", que, ainda segundo a polícia, permaneceram no local até a retirada dos manifestantes, o que acabou acontecendo após o agendamento de uma reunião entre o movimento social e a empresa, marcada para acontecer dois dias após a manifestação.

O pronto atendimento ao caso, para além da eficiência policial, chama a atenção para a relação Estado/Empresa/ Movimento Social. Nesse sentido, o "Relatório de Atividades Realizadas", publicado pelos propositores ainda quando do início das obras, menciona o repasse de recursos provenientes da empresa para um Quartel da Brigada Militar do Rio Grande do $\mathrm{Sul}^{7}$, sediado no município de Alpestre (RS). Conforme o referido documento, a empresa "repassou recursos para a instalação de um quartel da Brigada Militar do Rio Grande do Sul na comunidade Dom José, que se localiza próxima ao canteiro de obras". Ainda segundo o Relatório da empresa, "os recursos foram utilizados na compra de viatura, mobília e equipamentos, bem como na reforma do prédio utilizado", chegando ao valor de R\$ 130 mil (FCE, 2007: 3-5).

Ao questionarmos o diretor adjunto da empresa sobre o repasse de recursos para a polícia regional, especialmente no caso mencionado no Relatório, o entrevistado indagou:

Eu perguntaria assim: como você vê o fato de chegarem mais de 2000 operários numa cidadezinha dessas? São pessoas de todo o Brasil, com diferentes culturas

\footnotetext{
${ }^{6}$ POLÍCIA MILITAR DE SANTA CATARINA (PM/SC). Disponível em: $<$ www.pm.sc.gov.br/website/rediranterior.php?act=1\&id=3741 $>$. Acesso em: 25 nov. 2012.

${ }^{7}$ No Estado do Rio Grande do Sul (Brasil), a Polícia Militar (PM) recebe o nome de Brigada Militar (BM).
} 
que vão para um lugar pequeno, interiorano, precisa segurança ou não precisa? Daí você chega no governo e tem o problema do efetivo, da falta de recursos. Então, nós temos que fazer alguma coisa, já que nós causamos isso. [...] Se foi repassado uma viatura ou alojamento para a polícia, isso não vai resolver o problema em caso de uma invasão do canteiro, por exemplo, nesse caso é preciso efetivo de fora, não é isso que vai resolver.

A afirmação do diretor acerca do repasse de recursos à polícia, tendo em vista que a segurança pública ficou comprometida com o aumento populacional decorrente dos trabalhadores da obra, é plausível. Todavia, é preciso analisar a questão para além da relação direta de causa e consequência. Tendo em vista que as obras de grande escala são construídas a partir de Parcerias PúblicoPrivadas (PPP) que originam Sociedades de Propósitos Específicos (SPE), onde, embora o Estado seja acionista minoritário, chega a financiar $80 \%$ do projeto - sem mencionar os fundos de pensão que também participam como acionistas -, causa estranheza o repasse de recursos por parte dos propositores para instituições disciplinares como a polícia.

Considerando que o monopólio da violência seja atribuição do Estado, a partir do momento em que acontece uma aproximação entre o estatal e o privado, assim como ocorreu no caso em questão, faz sentido a ponderação de que essas articulações possam significar, no limite, a "privatização do monopólio da violência" (FON FILHO, 2008: 82). Na mesma linha e sob a perspectiva aqui tratada, é complementar a ideia de Faria (1989) ao indagar se as Parcerias Público-Privadas, não poderiam ser tomadas sob a forma de um processo de "publicização do privado e reprivatização do público" numa suposta "estratégia de despolitização dos conflitos e de sua posterior repolitização" em favor dos grupos mais poderosos na relação conflituosa (FARIA, 1989: 30).

A República brasileira passou por momentos de repressão acentuada em períodos como o Estado Novo (1938-45) e o Regime Militar (1964-85), não constituindo novidade a repressão. 
Porém, no contexto atual, essa ação não tem um condutor claro e específico como nos períodos citados anteriormente. No que concerne à questão da criminalização dos movimentos sociais ante essas obras de grande escala, ocorre que o próprio Estado (também proponente dessas obras) é quem media o conflito entre as empresas e os movimentos sociais no campo judicial. Disto, mesmo sob a consideração da independência entre os poderes estatais, não seria descabido especular sobre uma suposta posição privilegiada dos propositores das obras em relação aos seus opositores.

Sem que se determine a medida da influência desta parceria no trâmite judicial, esta sobreposição nos papéis reflete no fato de que a empresa, ao repassar recursos à polícia - mesmo que a obra conte com a participação do Estado -, propicia um ambiente de desconfiança sobre as ações policiais envolvendo essas obras de grande escala. Disto, a hipótese de "criminalização" dos movimentos sociais ganha consistência podendo ser entendida como estratégia dos propositores diante de um oponente que tem nas manifestações de pressão popular sua principal forma de ação.

\section{A legitimidade reclamada pelos movimentos sociais: os negros do século XVIII e os atingidos do século XXI}

Em boa parte das obras de grande escala que fazem parte tanto do PAC, podem ser identificadas mobilizações contrárias por parte dos movimentos sociais. Em todas as manifestações de vulto a força policial foi movimentada amparada no ideário legal ao passo que os movimentos sociais firmam suas demandas na legitimidade reclamada a partir das externalidades produzidas por essas obras.

Retomando ao caso que fundamenta empiricamente a nossa discussão, é exemplar o episódio envolvendo uma família que era proprietária de uma área de três hectares e arrendatária de outros pedaços de terra também na área do futuro canteiro de obras, onde desenvolviam atividades agrícolas. Em entrevista que fizemos com o agricultor, o mesmo relatou que 
na época quando tudo começou lá, quando começaram os trabalhos nos começamos também com o movimento junto, sendo adversário do consórcio. Então eles [FCE] me botaram polícia em cima, levei algum processo. Me botaram na cadeia, [...] não desisti, foi feito a busca e apreensão na minha propriedade, me acusaram de bandido, de [formação de] quadrilha, que eu tinha roubado e tudo. Não acharam nada! [...] Eu fui liberado agora, [...] mas eu ainda tenho uns cinco, seis, processo [na época da entrevista, em 2011].

Na media em que avançamos em nossa pesquisa de campo, a repetição da estratégia de pressão popular de integrantes de movimentos sociais foram seguidas de forma sistemática por ações de criminalização movidas pelos propositores da obra. Este cenário em muito lembrou o caso estudado por Thompson (1987) sobre os "Senhores e caçadores" da Inglaterra do século XVIII. Não obstante a diferença de contexto, lembramos que, naquele caso, os camponeses resistiram de forma organizada ("os negros") contra "cercamentos" restritivos impostos pela coroa sobre seu modo de vida. O enquadramento criminal daqueles como "quadrilhas" que atentavam contra um projeto que restringia o território com o apoio estatal, sugeriu-nos ponderações sobre o perfil dos acusados (negros do século XVIII e os movimentos sociais do século XXI) e a ação do poder instituído (Coroa inglesa daquela época e o Estado brasileiro atual.

Quanto aos acusados, enquadrados como "quadrilha" no século XVIII, o termo poderia se aplicar legalmente a qualquer grupo, "desde uma sociedade beneficente até um grupo de parentesco ou o salão literário de Fagin, que saísse fora da lei" (THOMPSON, 1987: 250). Na atual legislação brasileira, o Art. 288 do Código Penal criminaliza a ação de "mais de três pessoas, em quadrilha ou bando, para o fim de cometer crimes", sobre o que é prevista a pena de "um a três anos", aplicada em dobro se a suposta "quadrilha ou bando" agir armado (BRASIL, 1941). Disso, a primeira ponderação cabível é a de que, assim como os negros do século XVIII, mesmo que as ações dos atingidos acusados no século 
XXI apresentem traços legais de "quadrilha", para além do ponto de vista jurídico, o que precisa ser levado em conta é que este foi o recurso encontrado pelos mesmos num sentido "retributivo" ante "uma autoridade que ameaça sua economia, suas lavouras e seus direitos agrários costumeiros" (THOMPSON, 1987: 77).

Esta relativização da criminalização dos atingidos encontra outra situação análoga no caso inglês, no que se refere ao perfil individual dos acusados. Naquele caso, os acusados que acabaram sendo enforcados, em pouco se diferenciavam dos demais camponeses senão pelo fato de, "por má sorte ou pior avaliação, terem sido apanhados nas redes da lei". Thompson idealizou que se tivesse sido retirada "uma amostra casual de sete homens", para avaliar seu perfil criminológico, provavelmente o resultado seria muito parecido em relação aos demais, de forma que, se a resistência daqueles pudesse ser caracterizada como uma "subcultura criminosa, toda a Inglaterra plebeia entraria nessa categoria" (THOMPSON, 1987: 250). Analogamente, com base em nossa pesquisa empírica sobre o caso concreto, analisando a vida pregressa dos atingidos criminalizados de que tivemos ciência, não encontramos indícios contundentes que os qualifique como perigosos, de forma que - em caso de condenação - a resistência ante a forma como foi inserida a referida obra de grande escala seria o "fato" que os teria iniciado na "vida criminosa".

Nesse sentido, duas outras falas de atingidos criminalizados ajudam a ilustrar esta hipótese. Em entrevista que colhemos com outro agricultor que tinha sua propriedade na área do futuro canteiro de obras, o mesmo nos relatou o seguinte:

tu acredita que eles disseram que eu fiz uma quadrilha de bandido? Mas eu quero que tu saia agora daqui e vá perguntar de um por um na casa do pessoal aqui e peça se eu algum dia fiz alguma coisa pra alguém. [...] Eles chegaram na minha casa, nunca tinha vindo polícia aqui, e entraram e mexeram nas coisa. Eles pegaram uma espingarda véia que o polícia quis abrir ela e teve que desnucar na perna, porque não abria, tava tudo enferrujada, ninguém usava, aquilo lá eu tinha porque 
$\mid 208$ |

A criminalização dos movimentos sociais...

tá com nós desde os véio [avós] lá. Mas eles pegaram e disseram que eu tava ilegal com a minha espingarda.

Em outra entrevista que fizemos na mesma área do futuro canteiro de obras, outro agricultor relatou o cumprimento de um mandato de busca e apreensão realizado na sua propriedade:

Uma noite nós tava dormindo em casa a polícia chegou pra fazer uma busca. O piá [menino] que tava ali em casa foi olhar pelo buraco da corrente da porta e o polícia já gritou lá de fora: "é a polícia"! [...] Eu lembro que o polícia mexeu nas coberta da cama do outro piá com o cano da espingarda. Entraram, vasculharam e sabe o que que eles prenderam? Uma motosserra véia do finado pai que eu trouxe aqui pra tentar fazer funcionar. Pois tu acredita que eles queriam nota [fiscal] da motosserra? [...] Daí foram e queriam levar o motor da trilhadeira que não tinha nota [fiscal]. Eu disse que podiam levar porque eu não tinha nota dessas coisa que é tudo ainda do tempo do pai. O motor eles acabaram não levando, daí me chamaram pra pegar a motosserra lá na delegacia. Mas daí eu disse: "se ela tava ilegal, pois que agora pra mim ela tá mais ilegal ainda, podem prender ela aí". E não fui atrás. Porque daí na verdade o ladrão mesmo foi eles, tu não acha?

Com base nas entrevistas realizadas, é possível estabelecer um perfil predominante entre os atingidos criminalizados em função do protesto ante esta obra de grande escala. Não se trata de apresentarmos esses agricultores como pessoas incapazes de qualquer ato violento, porém, é preciso analisar o caso a partir do contexto social em questão e não somente pelo aspecto técnico do direito. É possível que se recorrermos a região, provavelmente encontraremos muitos casos de porte ilegal de arma, equipamentos sem nota fiscal ou mesmo relações trabalhistas fora da legislação vigente. Porém, o que precisamos ter em vista é o modo de vida dessas pessoas que estabelecem essas práticas como estratégias de vida no meio rural, o que foi drasticamente alterado pela chegada 
desta obra de grande escala que acabou instituindo uma lógica diferente para as relações sociais.

Outro ponto de nossa analogia recai sobre a ação do poder instituído, a dizer, a Parceria Público-Privada responsável pela obra. No caso inglês, a estratégia de criminalização "permitiu à Lei assumir, com seus mantos, a postura da imparcialidade: era neutra em relação a todos os níveis entre os homens, e defendia apenas a inviolabilidade da propriedade das coisas" (THOMPSON, 1987: 282). Transpondo a ideia para o caso atual, ratificamos a ideia da "criminologia crítica" segundo a qual as ações dos acusadores não se baseiam no contexto em que esses "crimes" são cometidos, que seja, a agressão ao modo de vida dessas pessoas, as indenizações aquém do que acreditam ser o justo, ou mesmo a negação dessas. $\mathrm{O}$ que é colocado em análise é exclusivamente o dano à propriedade privada, a partir do que, assim como defende o autor ao estudar o caso inglês, concordamos que por parte dos órgãos competentes, seja preciso fazer "alguma coisa", no sentido de equacionar o problema, todavia, isso não implica na possibilidade de se fazer "qualquer coisa" (THOMPSON, 1987: 252), sobretudo a repressão aos que discordam da forma como é conduzida a obra.

Retomando o binômio legal/legítimo para assinalar que o segundo passa em determinado momento pelo primeiro, no caso concreto o movimento social recorreu à Secretaria Especial dos Direitos Humanos (SEDH). Através do registro de denúncia de violações dos direitos humanos na região da obra, foram apontados como supostos responsáveis "órgãos públicos, empresas, poder judiciário e policias militares". Segundo a denúncia, sendo que essas violações se caracterizariam através de "ameaça, agressão física, intimidação e difamação contra indivíduos e grupos que promovem e protegem os direitos humanos" (SEDH, 2007). Disso, o órgão competente (SEDH) realizou visitas à região gerando um Relatório do qual destacamos as principais "conclusões" e "recomendações" a que chegou a Secretaria.

O Relatório concluiu que "os defensores dos direitos humanos" enfrentam processos civis e criminais decorrentes da própria violação dos seus direitos, sendo que a resistência diante 
desta situação, encampada pelos movimentos sociais, segundo a mesma comissão, "representa um valioso aporte para a democracia brasileira" (SEDH, 2007). Reconhecida a violação denunciada pelo movimento social, a mesma Secretaria "recomendou" aos governos estaduais que melhorassem o treinamento das polícias em observância com as recomendações das Nações Unidas quanto aos Direitos Humanos. Ao governo federal, "recomendou" a "criação de mecanismos para supervisionar o desempenho dos seus órgãos" bem como os "atrasos na implementação dos programas sociais" pertinentes às obras. Para a empresa, a "recomendação" foi de "retirar as ações que propôs contra defensores de direitos humanos", tendo em vista tratar-se "de problema social das populações atingidas e não mera questão jurídica ou caso de polícia". Finalmente, em relação ao judiciário, foi "recomendada" a revisão "do seu posicionamento de agente punitivo e garantidor do direito de propriedade, passando a ter papel pró-ativo no sentido de garantir também a implementação de políticas sociais pelo Estado, previstas na Constituição" (SEDH, 2007).

O caso da obra de grande escala que tomamos como exemplo concreto bem como outras obras que integram o PAC e compõem Relatórios em nível nacional, corroboram o que foi dito aqui sobre o binômio legal/legítimo. Porém, analisando o conflito entre as duas lógicas, podemos dizer que, mesmo o movimento social recorrendo ao órgão legalmente competente (SEDH), os caracteres de "conclusões" e "recomendações", embora condizentes com as denúncias, não chegam a exercer pressão sobre os propositores das obras, enquanto denunciados, o que reforça a possibilidade da legalidade suplantando a legitimidade fazendo da criminalização dos movimentos sociais um significativo fator de desequilíbrio nas relações de poder referentes aos projetos de grande escala no Brasil. 
|211|

Humberto José da Rocha

\section{Considerações finais}

O binômio legal/legítimo perpassa os processos de instalação de obras de grande escala. Os propositores reunidos em Parcerias Público-Privadas (PPP) encampam o caráter legal ao passo que os atingidos representados pelos movimentos sociais apoiam-se na legitimidade dos seus direitos ante as externalidades decorrentes dessas obras. Não tendo legalizado o que consideram legítimo, esses atingidos lançam mão de ações de pressão popular no intuito de chamar a atenção da opinião pública e pressionar os propositores para o atendimento das suas demandas. Por outro lado, as empresas detentoras da legalidade dos projetos procuram agregar a legitimidade dos mesmos para a sua concretização.

A criminalização representa o momento em que a reciprocidade entre o legal e o legítimo, necessária para ambos, sofre um severo desequilíbrio. A análise descontextualizada do judiciário sobre os casos tende a resumir todo o processo de instalação dessas obras apenas ao "fato típico" caracterizado como ação criminosa do atingido, desconsiderando a complexidade que abrange a resistência deste ante a agressão ao seu modo de vida. A sobreposição do público e do privado através das Sociedades de Propósitos Específicos (SPE) torna nebuloza a ação de criminalização. Iniciativas como o repasse de recursos da iniciativa privada para instituições disciplinares como a polícia - mesmo justiticado pelas circunstâncias das obras -, coloca em dúvida a ação policial num eventual conflito envolvendo os propositores que passam a aparelhar a polícia e os movimentos sociais que buscam resistir.

Nossa análise se concentrou no caso de uma obra de grande escala instalada no sul do Brasil, a UHE Foz do Chapecó. Todavia, o acompahamento do andamento das obras que compõem o PAC e os megaeventos esportivos permite sugerir que a criminalização dos movimentos sociais representa uma estratégia sitemática na concretização dos projetos. As obras dos megaeventos esportivos espalhadas por todo o país, especialmente nas cidades que sediarão jogos da competição, também têm suscitado debate e mobilizações 
sociais. Embora não tenham sido objeto da nossa análise, iniciativas como a Articulação Nacional dos Comitês Populares da Copa (ANCOP), que reúne comitês locais nas cidades sedes desse evento, especialmente o Comitê do Rio de Janeiro, cidade que ainda acumula experiências da preparação para os Jogos Olímpicos (2016), também são importantes pontos de análise. Nas principais manifestações organizadas nesses locais podem ser identificadas ações similares ao que foi apresentado no caso que abordamos.

As conquistas dos movimentos sociais ao longo da história não podem ser ignoradas. A tecnologia, as novas demandas e formas de associativismo têm permitido novas formas de mobilização. No que tange às obras de grande escala, uma ambiguidade inerente atrai interesses e grupos distintos onde na maioria das vezes não é simples o equilíbrio entre os ganhos de uns em decorrência das perdas de outros. A recorrência dos movimentos sociais aos órgãos de Direitos Humanos tem se mostrado, até o momento, insuficientes na tentativa de agregar legalidade à legitimidade dos direitos dos atingidos. A pressão popular tem sido alvo de ações legais movidas pelos propositores de forma a inibir as ações contrárias às obras. Nesse cenário, e por tudo o que apresentamos aqui, é que a criminalização dos movimentos sociais representa um elemento estratégico na assimetria das relações de poder na instalação de obras de grande escala.

\section{Bibliografia}

ANDRADE, V. R. P. Sistema penal máximo versus cidadania mínima: códigos de violência na era da globalização. Porto Alegre: Livraria do Advogado, 2003.

- A ilusão de segurança jurídica: do controle da violência à violência do controle penal. Porto Alegre: Livraria do Advogado, 1997. 
BARATTA, A. Criminologia crítica e crítica do direito penal: introdução à sociologia do direito penal. 3. ed. Rio de Janeiro: Renavan: Instituto Carioca de criminologia, 2002.

BONAVIDES, P. Ciência Política. 18. ed. São Paulo: Malheiros Editores, 2011.

BRASIL. Código de Processo Penal. Decreto-Lei n. 3.689, de 3 de Outubro de 1941.

BUHL, K.; KOROL, C. (Orgs.). Criminalização dos protestos e movimentos sociais. São Paulo: Instituto Rosa Luxemburg Stiftung: Rede Social de Justiça e Direitos Humanos, 2008.

FARIA, J. E. "O modelo liberal de direito e Estado". In: FARIA, J. E. (Org.). Direito e justiça: a função social do judiciário. São Paulo: Ática, 1989.

FON FILHO, A. "Criminalização dos movimentos sociais: democracia e repressão dos direitos humanos". In: BUHL, K.; KOROL, C. (Orgs.). Criminalização dos protestos e movimentos sociais. São Paulo: Instituto Rosa Luxemburg Stiftung: Rede Social de Justiça e Direitos Humanos, 2008.

FOZ DO CHAPECÓ ENERGIA S.A. Relatórios de Atividades Realizadas: Melhorias na região do canteiro de obras. ChapecóSC, 24 jul. 2007.

GOHN, M. G. História dos movimentos sociais no Brasil: a construção da cidadania dos brasileiros. 7. ed. São Paulo: Edições Loyola, 2012.

HABERMAS, J. Direito e democracia: entre facticidade e validade. 2. ed. Rio de Janeiro: Tempo Brasileiro, 2003. (vol. 2)

MIRABETE, J. F. Manual de direito penal. 20. ed. São Paulo: Atlas, 2003.

MOVIMENTO NACIONAL DE DIREITOS HUMANOS - MNDH. A criminalização dos movimentos sociais no Brasil: relatório de 
casos exemplares. (Organizado por Rosiana Pereira Queiroz). Brasília: MNDH; Passo Fundo: IFIBE, 2006.

POULANTZAS, N. O estado, o poder, o socialismo. Rio de Janeiro: Graal, 1981.

RIBEIRO, G. L. “¿Cuánto más grande mejor? Proyectos de gran escala: una forma de producción vinculada a la expansión de sistemas económicos". Buenos Aires, Desarrollo Económico, n. 105, Vol. 27, abr-jun 1987, pp. 3-27.

ROCHA, H. J. Relações de poder na instalação de hidreletricidade. Passo Fundo: EDIUPF, 2013.

. A condição de atingido por barragem. Anais do I Seminário Internacional e III Seminário Nacional: Movimentos Sociais, Participação e Democracia. Núcleo de Pesquisa em Movimentos Sociais (NPMS) - Universidade Federal de Santa Catarina (UFSC). Florianópolis-SC, 11 a 13 de agosto de 2010.

SANTOS, B. S. "Para uma sociologia das ausências e uma sociologia das emergências". Revista Crítica de Ciencias Sociais, Coimbra, 2002, n. 63, pp. 237-280.

. "Poderá o direito ser emancipatório?" Revista Crítica de Ciências Sociais, Coimbra/Portugal, 2003, n. 65, pp. 3-76.

SCHERER-WARREN, I. Redes de movimentos sociais. 3. ed. São Paulo: Loyola, 2005.

SEDH. Secretaria Especial dos Direitos Humanos. Relatório do Caso Foz do Chapecó. Brasília, 29 de setembro de 2007.

THOMPSON, E. P. Senhores e caçadores: a origem da lei negra. Rio de Janeiro: Paz e Terra, 1987.

Recebido em 02/09/2013.

Aprovado em 13/05/2014. 